\title{
Exploration and Application of Teaching Mode for Educating and Training Outstanding Civil Engineers
}

\author{
Chunli Wang ${ }^{\mathrm{a},}$ Jian $\mathrm{He}^{\mathrm{b}}$, Hairong $\mathrm{Mi}^{\mathrm{c}}$, Di Guan, Linan Zhu, Hongyu Lu \\ College of Aerospace and Civil Engineering, Harbin Engineering University, Harbin, 150001, \\ Heilongjiang, China \\ aspring555555@126.com, bhejian@hrbeu.edu.cn, cmihairong@hrbeu.edu.cn
}

\begin{abstract}
Keywords: Teaching method, outstanding civil engineers, Problem Based Learning, Case Based Learning
\end{abstract}

\begin{abstract}
For cultivating civil engineering undergraduate students to be qualified outstanding civil engineers with many innovative ideas, the educational reform is imperative. How to create an efficient teaching mode has become a prominent problem. On the base of detailed research of PBL and $\mathrm{CBL}$ teaching modes, new type PBL+CBL teaching model has been built with Engineering Project Management of civil engineering professional course. Then, the model is used to do the teaching practice and make the corresponding teaching evaluation. PBL+CBL teaching model is verified in the teaching of the effectiveness of the application, provide a reference for civil engineering courses teaching and reference. The exploitation and utilization of PBL+CBL teaching model in engineering courses is effective. Which provides a reference for civil engineering courses teaching.
\end{abstract}

\section{Introduction}

The weakness of engineering design and engineering innovation ability of university graduates have become a realistic and necessary problem in the process of educating and training outstanding engineers. One of the reasons is that the traditional teaching method of Engineering Teaching (Lecture Based Learning, LBL) is an instillation mode combined with a single sermon and practice, and the students accept knowledge passively and have their limitations. We try to apply the teaching mode of Problem Based Learning (PBL) and the teaching method based on the engineering case (Case Based Learning, CBL). Through the implementation of the teaching mode of PBL+CBL, it has aroused the students' enthusiasm for learning, enriching the teaching content, and making the engineering theory knowledge and Engineering set up. According to the close combination of practice, the students' ability to think independently and analyze the problems is trained, the students' thinking ability is trained, the basic qualities of the excellent engineers are created, and the foundation for the smooth transition of the students to the role of the engineers after graduation is laid.

\section{Analysis of PBL+CBL teaching mode and construction of teaching mode}

PBL and seminar teaching methods are popular teaching methods in Colleges and universities. PBL refers to problem-based learning or problem-based learning. It is a learning process based on problem and guided by teachers, focusing on students and focusing on a specific topic. [1-4] In PBL teaching, active learning runs through the whole process, students become autonomous or self-regulated learners, and students acquire knowledge mainly on their own. At present, PBL teaching method has been widely tried in many medical schools at home and abroad, and its teaching effect has obvious advantages. But there are also some defects: for students of primary school, for example, the theoretical knowledge of various disciplines, especially the interrelated theoretical knowledge of various disciplines, hinders the grasp of a comprehensive and coherent knowledge of knowledge. For students with poor self-study ability, it is difficult for them to receive a good learning effect in a short time. PBL teaching requires students to have a strong self-learning 
ability. It is necessary to read the literature and consult the information on the basis of extracurricular problems. It may be difficult for the undergraduate students who are accustomed to the traditional teaching. At the same time, before PBL teaching, students need to spend a lot of time preparing for class and consulting literature, which has increased the academic burden of undergraduate students.

CBL is a teaching model based on case. It carries out group discussion teaching in the form of learning cases, and closely links with practice [5]. CBL teaching mode is improved on the basis of PBL teaching, and the advantages of PBL teaching are assembled. Teachers use selected case materials to allow students to find out the process of solving problems through data access and independent analysis and train their thinking ability. Finally, teaching teachers explain the examples and properly join the latest research progress in the latest field. The earth fostering the students' practical ability in engineering practice. But the simple application of CBL teaching, each class can only learn a limited number of typical cases, and the problems encountered in the actual work are different, complex and diverse, and the theoretical learning of the classroom is far from the ability to cultivate the students' careful response to thinking, independent analysis and solving problems.

Therefore, it is necessary to combine PBL and CBL teaching methods for teaching. In the course of learning, students need to have the spirit of active inquiry, and they need to be self excited to set up their learning goals, to study independently, to conduct self-directed learning, and to apply the newly constructed knowledge to the complex problem solving. When they solve the problem, they will learn to become an independent thinker and learner, and truly learn, think and act together with. There are a lot of research topics on the subject of PBL or CBL at home and abroad, but most of them are based on the theoretical analysis based on static research, or in the scope of primary and secondary schools, and in the practical research of undergraduate teaching in Colleges and universities, there are not much research on the case of PBL+CBL teaching mode involving the identity of the researchers. This study takes the implementation process of PBL+CBL teaching mode in the management of civil engineering courses as a case to carry out a specific observation and analysis. By summarizing the implementation of PBL+CBL in the teaching, and drawing on the foreign $\mathrm{PBL}+\mathrm{CBL}$ theory research results and practice research experience, we can explore the autonomy of undergraduate students in our country. The theoretical model of learning, the construction of resources, the operating rules and the actual effect of education, and constructing a practical and cooperative PBL+CBL teaching model conforming to the concept of contemporary higher education.

The PBL+CBL teaching mode is constructed under the guidance of the brand-new educational thought, and its operability is very strong. The basic teaching process includes selecting typical cases, designing problems, guiding students to learn themselves, organizing discussion and summarizing, statistical analysis, and forming summary and reflection. In the course of engineering project management of civil engineering, the teaching effect is evaluated by the way of PBL+CBL teaching model and the way of self-evaluation and evaluation of others.

\section{Analysis of the effectiveness of using PBL+CBL teaching model}

The PBL+CBL teaching mode has been applied in two term in the project management course. 105 students of grade 2015 are randomly divided into 4 experimental groups and 3 experimental groups with 83 points of 2014. The experimental group adopts the PBL+CBL teaching method, and the control group has adopted the traditional teaching method. After the end of the course teaching, the students of the class were investigated from three aspects of teachers, students and courses, and the results showed that the results of the teaching were obvious.

(1) PBL+CBL teaching mode has stimulated students' interest in learning.

The implementation of PBL+CBL teaching mode is to break the new model of teacher oriented and student oriented. Under the strong interest of the case discussion, the students can stimulate the active and active discussion form of the group members, and the students can broaden their horizons according to their own thinking or others' thinking in the teaching activities. Rich 
knowledge has greatly improved the depth and breadth of understanding and mastery of knowledge; students turn from "paper talk" to "real guns", fully exercise and cultivate the ability of students to acquire knowledge and the ability to use modern information tools, which will have a far-reaching impact on the work of the future workers.

(2) PBL+CBL teaching mode fostered students' team spirit.

The solution to students' inquiry problem is the central link of PBL teaching mode. This research is completed in the form of "group cooperation". Team members in the process of exploring the problem through in-depth exchanges, to improve the degree of familiarity with each other, and formed the basic qualities of the members of the scientific research team, who are good at cooperation, and are brave to take responsibility. Team members have strengthened their team spirit when they jointly seek engineering management programs. This process not only improves the ability of the group members to debate and the self-regulation and error correction of the group, but also improves the ability to disagree with the members of the group and the ability to share their own ideas and opinions. . The questionnaire survey shows that $95 \%$ of the students believe that the implementation of the PBL+CBL teaching model has developed their own sense of teamwork and ability to make themselves feel a positive atmosphere in the team.

(3) PBL+CBL teaching mode improves students' awareness of scientific research.

The implementation of PBL+CBL teaching mode requires students to solve their own research topics on their own with the content of professional courses. This allows students to understand the research work, stimulate their curiosity, improve their interest in scientific research, experience the fun of academic research, and stimulate students' innovative ability. At the same time, correct students' attitude towards scientific research and enhance their awareness of scientific research.

At the same time, the new teaching method is more challenging for teachers' work, and requires higher teaching quality for teaching preparation stage and teaching implementation stage. This teaching mode is not only conducive to promoting students' learning, establishing a three-dimensional, comprehensive and systematic multi-dimensional knowledge system, but also improving teachers' comprehensive quality.

\section{Conclusion}

The rapid development of society and economy has stimulated the continuous improvement of education and teaching. Outstanding engineer education has gradually become the main theme of the field of Engineering Education in twenty-first Century. On the theoretical level, this study constructs the PBL+CBL teaching model of the civil engineering courses; in practice, the $\mathrm{PBL}+\mathrm{CBL}$ teaching platform is set up, and the teaching practice is carried out. It verifies the effectiveness of PBL+CBL teaching mode in engineering courses teaching. It is helpful to change the wrong understanding of "engineering education = Science Education (Humanities Education)", enrich and perfect the teaching theory of higher engineering education through in-depth research and explore the teaching mode of practical ability training for outstanding civil engineers, and provide reference for further promoting the training of excellent engineers.

\section{Acknowledgement}

In this paper, the research was sponsored by the Research Project on Teaching Reform of Harbin Engineering University (JG10217Y07); the Innovation Project of Seven Education in Harbin Engineering University ("Research and Practice on Education Mode of Engineering Ethics Based on the Outstanding Engineers Training Plans"); the Research Project on Teaching Reform of Harbin Engineering University (JG2016BYB06, JG10217Y05); the Innovation Project of Seven Education in Harbin Engineering University ("Practice on the Values Education Mode of Introductory Course Teaching” and ("Research on Approaches and Countermeasures of Restoring the Academic Integrity for Postgraduate Students”). 


\section{References}

[1] Boud,D. ,Feletti,G..The Challenge of Problem-Based Learning.St.Martin’s Press Inc. [Z]1991

[2] Donald R. Woods. Problem-based learning: How to gain the most from PBL[M].First ed. Pbl Waterdown, Ontario: Danald R. Woods,1994

[3] Lloyd-fones,G.et.al.. Problem-Based Learning: A Coat many Colors. Medical Education[J], 199832 492-494

[4] Anette Kolmos, Flcmming K·Fink, Lone Krogh. The Alborg PBL model [M].Alborg: Alborg University Press, 2006

[5] A. V. Jamkar, W. Burdick, P. Morahan, et.al..Proposed model of case based learning for training undergraduate medical student in surgery [J]. Indian Journal of Surgery, 200769 (5) 176-183 